\title{
Extrinsic Motivation and Perceived Benefits of Environmental Volunteering: Perspectives from Students
}

\author{
Norshariani Abd Rahman*, Alya Nasuha Abdul Rahman \\ Institute of Islam Hadhari, Universiti Kebangsaan Malaysia, Bangi, Malaysia \\ Email: *norshariani@ukm.edu.my
}

How to cite this paper: Rahman, N. A., \& Rahman, A. N. A. (2021). Extrinsic Motivation and Perceived Benefits of Environmental Volunteering: Perspectives from Students. Creative Education, 12, 2792-2805. https://doi.org/10.4236/ce.2021.1212206

Received: October 23, 2021

Accepted: December 4, 2021

Published: December 7, 2021

Copyright (c) 2021 by author(s) and Scientific Research Publishing Inc. This work is licensed under the Creative Commons Attribution International License (CC BY 4.0).

http://creativecommons.org/licenses/by/4.0/ (c) (i) Open Access

\begin{abstract}
Environmental volunteering has proven to be a valuable tool for environmental conservation and students' self-development. However, to maximise the benefits of environmental volunteering programs, stakeholders should understand the factors that motivate school or university students to participate in environmental volunteering. In addition, the perceived benefits gained, from the students' perspectives, will help to sustain and retain the level of volunteering among students. Therefore, this study examined the extrinsic motivation and benefits of environmental volunteering participation from the students' perspectives. There are three (3) subconstructs for extrinsic motivation: social influences, fulfilling school or university requirements and cultures. Meanwhile, the benefits have four (4) subconstructs: positive emotion, meaningfulness, relationship and achievements. Random sampling was used and a survey was conducted among 356 students who had experience of environmental volunteering (aged 15 - 30 years old). Descriptive analysis was employed to analyze the level of extrinsic motivation and perceived benefits of environmental volunteering. Meanwhile, the t-test was employed to analyze the differences in levels of extrinsic motivation and perceived benefits based on gender. The results indicate that extrinsic motivation and perceived benefits were at a high level. However, there was no significant difference in terms of extrinsic motivation and perceived benefits based on gender. This study used students' perspectives to highlight the role played by extrinsic motivation and environmental volunteering benefits in retaining participation in environmental volunteering. In addition, this study could help to strengthen environmental education through students' environmental volunteering to achieve sustainable development goals.
\end{abstract}

\section{Keywords}

Environmental Volunteer, Environmental Education, Extrinsic Motivation, 
Environmental Conservation, Social Work

\section{Introduction}

Environmental damage and the escalating issue of climate change require urgent large-scale cooperation in combination with individual environmental behaviour (Doherty \& Webler, 2016). Environmental volunteering is one example of largescale collective environmental management. Through environmental volunteering, the government can save the environmental management costs while having a positive impact on the environment and the individuals involved, especially students. In addition, environmental volunteering is a platform for students to apply hands-on environmental education and support sustainable development agenda. Among these goals are the $4^{\text {th }}$ SDG (quality education), $13^{\text {th }}$ SDG (climate action) and $11^{\text {th }}$ SDG (sustainable cities and communities). In addition, environmental volunteering also supports Global Citizenship, which seeks to raise the levels of community involvement in environmental management.

Environmental conservation NGOs play an important role in providing opportunities for students to get involved as environmental volunteers. Environmental volunteering programs are extended to educational institutions that play a role in educating students on environmental sustainability. However, the dropout rate among environmental volunteers has often resulted in the goals of environmental volunteer programs not being achieved. Organisations or organisers of such programs also face problems in training new volunteers. Thus, there is a need to study the factors that contribute to the sustainability of environmental volunteer involvement.

Past studies have revealed research trends that examine the motivation for involvement as an environmental volunteer. The motivations studied are divided into two main factors, namely intrinsic motivation, which refers to values, attitudes and awareness; and extrinsic motivation, i.e. social influence, media influence, campaigns and incentives obtained after becoming involved as an environmental volunteer. However, past empirical studies have focused more on intrinsic motivation factors, based on existing theories (Measham and Barnett, 2008; Woosnam et al., 2019). Meanwhile, extrinsic factors are still insufficiently studied (Smith et al., 2010; Fang et al., 2017), especially in the context of volunteerism among students. By understanding extrinsic motivation, stakeholders involved with educational institutions can provide support by providing circumstances that support the sustainability of student involvement as environmental volunteers.

The motivation to engage in environmental volunteer activities also relates to the benefits felt by environmental volunteers if they become involved in this way. The benefits felt by the students would become a motivation to repeat their involvement as environmental volunteers. Among the reported benefits of environmental volunteering to volunteers are improved physical health, improved 
mental health, an expansion of their networks, improved social communication, a better knowledge of environmental management, practical experience of the working environment and being able to link knowledge to related fields of study (Patrick, Henderson-Wilson, \& Ebden, 2021; Lim \& Ibrahim, 2020). However, the benefits of environmental volunteerism in the context of students need to be studied so that the interventions of educational agents and their impact on sustainability can be considered.

The influence of volunteer demographics also informs the organisers of environmental volunteering programs and allows them to focus on target groups. Examples of these demographic factors are gender, age, socioeconomic status, field of education and level of education. However, little attention has been given to theories that explain pro-environmental behaviour by taking gender differences into account (Vicente-Molina, Fernandez-Sainz, \& Izagirre-Olaizola, 2018). Similarly, there are differences in involvement in environmental volunteering based on gender. Female volunteers were more likely than males to be motivated by social interaction, commitment and tradition (Larson et al., 2020). Meanwhile, according to Xiao and Hong (2018), men expressed more concern for the environment and were more involved in environmentally related activities (Piyapong, 2019). Thus, incorporating the findings about gender differences in extrinsic motivation and perceived benefits will serve to inspire women and men to engage in effective environmental volunteering.

Responding to that research gap, this paper attempts to examine the extrinsic motivation and perceived benefits of environmental volunteering from students' perspectives. In addition, this study investigates how differences in extrinsic motivation and benefits of environmental volunteering may be based on gender. Identifying factors that promote environmental volunteering has become a key task in forecasting future environmental needs and social trends, as well as in designing environmental volunteering programs, environmental education and policies which meet society's environmental demands.

\section{Literature Review}

\subsection{Extrinsic Motivation}

One's environment can influence their behaviour towards the environment, either voluntarily or forcibly. Based on the theory of planned behaviour (Ajzen, 2005), subjective norms or the person closest to an individual can influence that person's behaviour towards the environment. Among the closest people who can influence action on the environment are peers (Law, Shek, \& Ma, 2013), family (Van Goethem et al., 2014), parents (Van Goethem et al., 2014), teachers (Law et al., 2013; Caplow, 2018) and the local community (Gammoh et al., 2019). In addition, based on the Values-Beliefs-Norms (VBN) theory (Stern, 2000), norms are extrinsic factors that form the standards or rules that tell members of a group or society how they should behave (Schwartz, 2012). For this reason, the social roles and requirements of social environments and cultures influence environ- 
mental behaviour. Previous research showed that adolescents were more likely to volunteer when their best friend and parents volunteered (Van Goethem et al., 2014). Parents have a stronger influence on volunteering than friends (Smetana et al., 2006). Social support and role models can serve to reinforce social norms and inform individuals about their perceptions, effectiveness and behaviours, while they also support pro-environmental activities such as volunteering (Smith et al., 2010).

Research by Smith et al. (2010) found that the high levels of volunteerism among students' universities in five countries (Australia, Canada, New Zealand, the United Kingdom and the United States) demonstrated positive signs for educational institutions and governments seeking to promote volunteerism among students. Volunteer programs based on active campus activities by university clubs, sports clubs and cultural organisations also influence student involvement in volunteer activities. Most of these organisations are based on campus activities, so they are easily accessible to students and thus help in fostering environmental volunteering. However, little literature has been devoted to social influence (Law, Shek, \& Ma, 2013), school/university requirements and culture in relation to environmental behaviour (Fang et al., 2017).

\subsection{Benefits of Environmental Volunteering}

Environmental volunteering activities can improve the well-being felt by participants by reducing negative emotions, helping to overcome loneliness (Guiney \& Oberhauser, 2009; O’Brien et al., 2010; Kragh et al., 2016) and helping to overcome depression (Pillemer et al., 2010). In terms of personal development, environmental volunteering can improve relationships, knowledge, physical health, mental health and skills (Aydinli-Karakulak et al., 2016; Huang, 2018; Liarakou, Kostelou, \& Gavrilakis, 2011; Lu \& Schuett, 2014; Measham \& Barnett, 2008; Molsher \& Townsend, 2016). This perceived well-being has a long-term impact and is remembered even when the volunteer activity is over (Kragh et al., 2016).

Through the activities of environmental volunteering, volunteers indirectly develop a good relationship with the environment. Environmental volunteerism has a positive impact on improving the quality of the environment and the country as it saves environmental conservation costs. In addition, environmental volunteer activities provide opportunities for volunteers to spend time with nature, which contributes to a better relationship with volunteering values (Guiney \& Oberhauser, 2009). This can also mean volunteers understand the environment better (Koss \& Kingsley, 2010). Past studies have shown that relationships with the environment have an impact by improving health (Lovell et al., 2018), well-being (Capaldi et al., 2015; McMahan \& Estes, 2015) and pro-environmental attitudes (Arendt \& Matthes, 2016).

The benefits felt from involvement as an environmental volunteer are related to well-being. Seligman (2011) proposed a multi-dimensional well-being theory, known as the PERMA (Positive emotion, Engagement, Relationship, Meaning- 
fulness and Achievement) model, to explore the well-being of environmental volunteers. Previous studies have adapted the PERMA model to measure environmental volunteers' well-being or the benefits they experienced after engaging in environmental volunteering programs (Kragh et al., 2016; Butler \& Kern, 2016). The findings of such studies provide guidance to environmental volunteering organisers and educational institutions, helping them to plan environmental volunteering programs that suit the ability of students, as well as improve and retain the environmental volunteer participants.

Volunteers will stay with an organisation if they have high levels of personal commitment and feel satisfied due to various conditions: they should personally benefit from mentoring, training and professional development practices; perceive a match between their motivation and their given tasks; and work for an organisation with a good organisational reputation (Faletehan et al., 2020). The characteristics of the identity, image and reputation of the organisation tend to be important reasons why volunteers join and stay longer in non-profit groups (Faletehan et al., 2020).

\section{Research Methodology}

\subsection{Context of the Study}

This quantitative study aimed to examine the extrinsic motivation and benefits of environmental volunteering among students $(n=356)$. The data were obtained from students who had experience of environmental volunteering in the Klang Valley. The types of environmental volunteering activities in which the participants had been involved were diverse and mostly related to conservation, education and sustainable living.

\subsection{Respondents of the Study}

Purposive sampling was used in this study to identify the samples of the study. This method ensured that the participants could provide information to answer the research questions. The participants were youths, i.e., those aged between 15 and 30 years old, who had been involved in environmental volunteering activities. The respondents involved in this study were representatives of environmental volunteers. A total of 356 respondents participated in this study; of which 90 were male $(25.3 \%)$ and 266 were female $(74.7 \%)$.

\subsection{Data Collection Procedure}

A questionnaire was distributed to 356 student environmental volunteers using Google forms and with instructions from a research assistant. The use of Google forms is faster and simpler because data would be displayed through Excel. The questionnaire instrument was developed by the researcher and adapted from previous research. The Cronbach's alpha obtained was high so the study instrument was considered suitable for use in this study. The Cronbach's alpha values are presented in Table 1. 
Table 1. Cronbach's Alpha Values for extrinsic motivation and benefits of environmental volunteering.

\begin{tabular}{ccc}
\hline No. & Construct & Cronbach's Alpha Value \\
\hline 2 & Extrinsic motivation & .898 \\
3 & Benefits of environmental volunteering & .985 \\
& Overall & .962 \\
\hline
\end{tabular}

\subsection{Instruments Development}

A structured questionnaire was developed. A sample of 356 environmental volunteers was obtained. Forty-five questionnaires were discarded because they were incomplete or completed by non-students, resulting in a valid sample of 356 individuals. The questionnaire was divided into three (3) sections. The first section comprised the demographics of the respondents, such as their gender, status, name of school/university/employer, field of education, level of education, name of environmental volunteering program and duration of being involved in an environmental volunteering program. However, only gender was analysed for this paper. The second section referred to extrinsic motivation (15 items) that consisted of social influences, requirements and cultures. The third section referred to the benefits of environmental volunteering (25 items), i.e., positive emotion, meaningfulness, relationship and achievements. The second and third sections were measured using self-report items on a 10-point Likert scale, depending on whether participants agreed or disagreed with each statement. The scales for these factors were developed after considering the findings from interviews with ten environmental volunteer study participants and adapting instruments used in previous relevant literature. Table 2 shows examples of the items used in the instrument in this research.

\subsection{Data Analysis Procedure}

Data analysis was performed using SPSS software. Two types of data analysis were used for this study: descriptive and inferential analysis. Descriptive analysis involved mean and standard deviation while inferential analysis involved the t-test. To measure the level of environmental extrinsic motivation and the benefits of environmental volunteering, mean interpretation by Nunnally (1997) was referred to, as shown in Table 3. In addition, the t-test was employed to compare extrinsic motivation and benefits of environmental volunteering, based on gender.

\section{Findings of the Study}

\subsection{Level of Extrinsic Motivation and Benefits of Environmental Volunteering}

The overall mean scores for extrinsic motivation and the benefits of environmental volunteering is shown in Table 4. Based on Table 4, the level of extrinsic 
Table 2. Constructs and subconstructs of the questionnaire.

\begin{tabular}{|c|c|c|c|}
\hline No. & Contructs & Subcontructs & Examples of items \\
\hline \multirow{3}{*}{2} & \multirow{3}{*}{$\begin{array}{c}\text { Extrinsic } \\
\text { Motivations }\end{array}$} & Social Influences & $\begin{array}{l}\text { I am involved in environmental volunteer } \\
\text { activities because of influence from the } \\
\text { organisers }\end{array}$ \\
\hline & & Requirements & $\begin{array}{l}\text { I am involved in environmental volunteer } \\
\text { activities to meet the requirements of the club } \\
\text { or association involved }\end{array}$ \\
\hline & & Cultures & $\begin{array}{l}\text { I am involved in environmental volunteer } \\
\text { activities because this follows the practice of } \\
\text { helping in the community }\end{array}$ \\
\hline \multirow{4}{*}{3} & \multirow{4}{*}{$\begin{array}{c}\text { Benefits of } \\
\text { environmental } \\
\text { volunteering }\end{array}$} & Positive emotion & $\begin{array}{l}\text { After being involvement in environmental } \\
\text { volunteer activities, I am happy I have been } \\
\text { able to contribute to the environment }\end{array}$ \\
\hline & & Meaningfulness & $\begin{array}{l}\text { After being involved in environmental } \\
\text { volunteer activities, I feel grateful I have been } \\
\text { able to help preserve the environment as } \\
\text { required in my religion }\end{array}$ \\
\hline & & Relationship & $\begin{array}{l}\text { After being involved in environmental } \\
\text { volunteer activities, I have been able to forge } \\
\text { closer ties with the local community }\end{array}$ \\
\hline & & Achievements & $\begin{array}{l}\text { After being involved in environmental } \\
\text { volunteering activities, I have been able to } \\
\text { spread a wide range of career fields }\end{array}$ \\
\hline
\end{tabular}

Table 3. Interpretation of mean scores for extrinsic motivation and benefits of environmental.

\begin{tabular}{cc}
\hline Mean Score & Interpretation of Mean Score \\
\hline $1.00-2.00$ & Low \\
$2.01-3.00$ & Moderately Low \\
$3.01-4.00$ & Moderately High \\
$4.01-5.00$ & High \\
\hline
\end{tabular}

Source: Nunnally (1997).

Table 4. Mean and standard deviation for extrinsic motivation and benefits of environmental volunteering.

\begin{tabular}{cccc}
\hline Constructs/Subconstructs & Mean & Standard Deviation & Mean Interpretation \\
\hline Total Extrinsic Motivation & 4.071 & .664 & High \\
Social Influences & 3.864 & .846 & Moderately High \\
Requirements & 4.020 & .844 & High \\
Cultures & 4.328 & .618 & High \\
Total Benefits of & & & High \\
Environmental Volunteering & 4.611 & .468 & \\
\hline
\end{tabular}


Continued

\begin{tabular}{cccc}
\hline Positive Emotion & 4.671 & .466 & High \\
Meaningfulness & 4.656 & .473 & High \\
Relationship & 4.556 & .566 & High \\
Achievements & 4.587 & .511 & High \\
\hline
\end{tabular}

motivation that the school/university students had was examined based on the three subscontructs: social influences, school/university requirements and cultures. Overall, the level of extrinsic motivation was high. Based on the extrinsic motivation subconstructs, only social influences was moderately high, while the other two subconstructs, namely school/university requirements and cultures, were high. The social influences employed in this study were the influence of friends, family, program organisers, teachers/lecturers and the government. In terms of the overall benefits of environmental volunteering, the subconstructs (positive emotion, meaningfulness, relationship and achievement) were all at a high level.

\subsection{Comparison of Extrinsic Motivation and Perceived Benefits of Environmental Volunteering Based on Gender}

\section{1) Comparison of Extrinsic Motivation Based on Gender}

Table 5 shows that overall, extrinsic motivation had no significant differences based on gender $(t=-.735, p=.463>.05)$. Thus, there were no significant differences in the values found for social influences $(\mathrm{t}=.578, p=.564>.05)$, school/ university requirements $(\mathrm{t}=-1.830, p=.068>.05)$ or cultures $(\mathrm{t}=-.671, p$ $=.502>.05)$ based on gender.

\section{2) Comparison of Benefits of Environmental Volunteering Based on Gender}

Table 6 showed there were no significant differences in environmental volunteering based on gender $(\mathrm{t}=-1.640, p=.104>.05)$. In addition, there were no significant differences in terms of relationship $(\mathrm{t}=-1.122, p=.263>.05)$ and achievement $(\mathrm{t}=-1.298, p=.197>.05)$ based on gender. However, there were significant differences in terms of positive emotion $(\mathrm{t}=-2.169, p=.032<.05)$ and meaningfulness $(\mathrm{t}=-2.091, p=.039<.05)$ between the male and female volunteers. Based on the mean scores, female volunteers showed higher positive emotion (mean $=4.708$, sd $=.408$ ) and felt more meaningfulness when participating in environmental volunteering (mean $=4.575$, sd $=.552$ ), compared to male volunteers. Both effect sizes for differences were at moderate levels.

\section{Discussion}

This study examined the extrinsic motivation and perceived benefits of students who had experience of being environmental volunteers. The findings show that extrinsic motivation and perceived benefits were at a high level among such students. The subconstruct of social influences, that is, the influence of friends, 
Table 5. $\mathrm{t}$-test for comparison of extrinsic motivation based on gender.

\begin{tabular}{|c|c|c|c|c|c|c|c|}
\hline Construct & Gender & No. & Mean & Standard Deviation & t Value & Significance Level & Effect Size \\
\hline \multirow{2}{*}{ Social Influences } & Male & 90 & 3.909 & .877 & .578 & .564 & .07 \\
\hline & Female & 266 & 3.849 & .836 & & & \\
\hline \multirow{2}{*}{$\begin{array}{l}\text { School/University } \\
\text { Requirements }\end{array}$} & Male & 90 & 3.880 & .944 & -1.830 & .068 & .214 \\
\hline & Female & 266 & 4.068 & .804 & & & \\
\hline \multirow{2}{*}{ Cultures } & Male & 90 & 4.290 & .632 & -.671 & .502 & .082 \\
\hline & Female & 266 & 4.341 & .613 & & & \\
\hline \multirow{2}{*}{ Extrinsic Motivation } & Male & 90 & 4.026 & .720 & -.735 & .463 & .088 \\
\hline & Female & 266 & 4.086 & .645 & & & \\
\hline
\end{tabular}

Table 6. t-test for comparison of benefits of environmental volunteering based on gender.

\begin{tabular}{cccccccc}
\hline \multirow{2}{*}{ Construct } & Gender & No. & Mean & $\begin{array}{c}\text { Standard } \\
\text { Deviation }\end{array}$ & t Value & $\begin{array}{c}\text { Significance } \\
\text { Level }\end{array}$ & $\begin{array}{c}\text { Effect } \\
\text { Size }\end{array}$ \\
\hline \multirow{2}{*}{ Positive emotion } & Male & 90 & 4.561 & .595 & -2.169 & $.032^{*}$ & .288 \\
& Female & 266 & 4.708 & .408 & & & \\
\hline \multirow{2}{*}{ Meaningfulness } & Male & 90 & 4.549 & .601 & -2.091 & $.039^{*}$ & .276 \\
& Female & 266 & 4.692 & .417 & & & \\
\hline \multirow{2}{*}{ Relationship } & Male & 90 & 4.498 & .606 & -1.122 & .263 & .133 \\
& Female & 266 & 4.575 & .552 & & & \\
\hline \multirow{2}{*}{ Achievement } & Male & 90 & 4.520 & .591 & -1.298 & .197. & .165 \\
& Female & 266 & 4.609 & .480 & & & \\
\hline \multirow{2}{*}{ Benefits } & Male & $\mathbf{9 0}$ & 4.530 & .582 & -1.640 & .104 & .215 \\
& Female & 266 & 4.639 & .420 & & & \\
\hline
\end{tabular}

family, program organisers, the government, teachers and lecturers, was at a moderately high level. Meanwhile, school or university requirements and cultures were at a high level. The findings of previous studies have also shown that peers, parents and family influence students' involvement as environmental volunteers (Van Goethem et al., 2014; Culiberg \& Gambier, 2016; Law et al., 2013). This is because students easily turn the person closest to them into a role model.

In addition, government support is essential in promoting environmental volunteerism as it creates opportunities for students to engage in environmental volunteer activities. For example, the Ministry of the Environment launched campaigns such as "Save the River" and "Earth Hour"; organised an "Environment Friends" program; and cooperated with environmental NGOs to increase the engagement with volunteers through such programs. In addition, the government also contributes financially to organisations such as environmental NGOs to encourage more volunteers to participate. The government has introduced environmental elements into education in Malaysia, so the role of the government 
in increasing the number of environmental volunteers cannot be overlooked. Education plays an important role in sparking environmental awareness (Binder \& Blankenberg, 2016).

Teachers or lecturers play an important role in encouraging undergraduate youths to engage in environmental volunteer activities as a form of community service in line with students' roles as change agents. The influence of teachers and lecturers is also indispensable. A school's attitude to adolescent volunteerism directly affects the subsequent level of participation (Law et al., 2013). Therefore, the role of teachers or lecturers is highly important in achieving the goal of sustainable development through environmental volunteering.

Cultural influences, such as helping and kindness, have become the norm in the community, leading to engagement in environmental volunteer activities. Societal roles tend to indicate how an individual perceives themselves within a group. The community-building component of the community function provides a useful way for organisations like NGOs, clubs, school/university associations and neighbourhood communities to foster a sense of community (Carpenter et al., 2016). Culture, which plays a major role in this, can be identified as it is reflected in the norms of a society. People generally often base their actions on either individualism or collectivistic thinking without consciously knowing it (Gammoh et al., 2019). In this study, the respondents could be categorised into having collectivistic personalities. Collectivistic individuals tend to be more influenced by group thought processes. They also tend to focus on long-term goals, such as which things would benefit the community and the protection of nature. These factors result in their participation in environmental volunteerism (Gammoh et al., 2019).

The perceived benefits of environmental volunteers in this study were almost the same as the findings of previous studies. The benefits involved the elements of emotions, competence, practice, a relationship with the environment and society, awareness, a meaningful life, feeling blessed by God and an appreciation of the activities performed (Seligman, 2011; Huppert \& So, 2013; Molsher \& Townsend, 2016; Rusk \& Waters, 2015; Wong, 2011). Since the participants of this study were students aged between 15 and 30, the benefits felt in terms of achievement related to the self-development of students, which could be applied in their lives. Among these were gaining communication skills, leadership, handling animals, problem solving, social self-confidence, improved environmental knowledge and health benefits. A study by Lim and Ibrahim (2020) found that personal growth is a major influence on involvement as an environmental volunteer, followed by the factor of purposive reasons (doing something worthwhile). Therefore, organisers of environmental volunteering programs need to consider the perceived benefits that students feel after engaging in environmental volunteer activities, which would allow the organisers to sustain and retain their rate of environmental volunteers.

This study found no significant difference in terms of the level of extrinsic 
motivation and perceived benefits of environmental volunteering based on gender. This finding contradicts previous research by Xiao and McCright (2015), who found that women showed relatively stronger environmental concern and behaviour than men. Sociological theories of gender emphasise that gender differences exist in the socialisation process, social roles and status in society (Xiao \& McCright, 2015). Women and men may play different roles in protecting the environment in terms of decision-making at community and domestic levels. Therefore, women and men may become socialised on the basis of the dominant culture in their society.

\section{Conclusion}

The study makes an important contribution to the area of environmental volunteering as it illustrates the extrinsic motivation and benefits among students who had experience of environmental volunteering. When volunteer retention rates are high, there will likely be greater opportunities to achieve the respective environmental volunteering objectives. The knowledge obtained from this study reveals not only new ways to empower current volunteers but also strategies for recruiting and retaining more diverse groups of environmental volunteers, as well as informing participants of the outcomes of their work.

This study also has several important theoretical implications. First, it investigates extrinsic motivation concerning the environment. Applying the theories of planned behaviour and values-beliefs-norms to measure extrinsic motivation (in terms of social influences, school/university requirements and cultures) and the benefits of environmental volunteering could be employed in predicting the sustainability of environmental volunteering participation.

These findings can be useful to help marketers and policy makers conduct more effective strategies that encourage men and women to engage in environmental volunteering programs. The results also have potential applications in education and contribute to our understanding of how students are presently dealing collectively with environmental problems through environmental volunteering participation. Redefining measures of gender not just as demographic factors but as female and male indicators of the gender identity of individuals might also help to test the validity of socialisation theory in explaining the differences identified in pro-environmental behaviour patterns and explanatory factors. Overall, this study provides practical implications for governments, non-government organisations (NGOs) and education institutions that conduct environmental volunteering programs.

\section{Acknowledgements}

This research was funded by FRGS/1/2018/SSI12/UKM/03/1, Ministry of Education and Universiti Kebangsaan Malaysia.

\section{Conflicts of Interest}

The authors declare no conflicts of interest regarding the publication of this paper. 


\section{References}

Ajzen, I. (2005). Attitudes, Personality and Behavior (2nd ed.). Open University Press.

Arendt, F., \& Matthes, J. (2016). Nature Documentaries, Connectedness to Nature, and Pro-Environmental Behavior. Environmental Communication, 10, 453-472. https://doi.org/10.1080/17524032.2014.993415

Aydinli-Karakulak, A., Bender, M., Ming, A., Chong, L., \& Yue, X. (2016). Applying Western Models of Volunteering in Hong Kong: The Role of Empathy, Prosocial Motivation and Motive-Experience Fit for Volunteering. Asian Journal of Social Psychology, 19, 112-123. https://doi.org/10.1111/ajsp.12125

Binder, M., \& Blankenberg, A. K. (2016). Environmental Concerns, Volunteering and Subjective Well-Being: Antecedents and Outcomes of Environmental Activism in Germany. Ecological Economics, 124, 1-16. https://doi.org/10.1016/j.ecolecon.2016.01.009

Butler, J., \& Kern, M. L. (2016). The PERMA-Profiler: A Brief Multidimensional Measure of Flourishing. International Journal of Wellbeing, 6, 1-48. https://doi.org/10.5502/ijw.v6i3.526

Capaldi, C. A., Passmore, H. A., Nisbet, E. K., Zelenski, J. M., \& Dopko, R. L. (2015). Flourishing in Nature: A Review of the Benefits of Connecting with Nature and Its Application as a Wellbeing Intervention. International Journal of Wellbeing, 5, 1-16.

https://doi.org/10.5502/ijw.v5i4.449

Caplow, S. (2018). The Presentation of Environmental Values, Beliefs, and Norms in Live Animal Interpretive Experiences. Environmental Education Research, 25, 1-16. https://doi.org/10.1080/13504622.2018.1479837

Carpenter, S., Takahashi, B., Cunningham, C., \& Lertpratchya, A. P. (2016). The Roles of Social Media in Promoting Sustainability in Higher Education. International Journal of Communication, 10, 4863-4881

Culiberg, B., \& Gambier, L. E. (2016). Going Green to Fit In-Understanding the Impact of Social Norms on Pro-Environmental Behaviour, a Cross-Cultural Approach. International Journal of Consumer Studies, 40, 179-185. https://doi.org/10.1111/ijcs.12241

Doherty, K. L., \& Webler, T. N. (2016). Social Norms and Efficacy Beliefs Drive the Alarmed Segment's Public-Sphere Climate Actions. Nature Climate Change, 6, 879-884. https://doi.org/10.1038/nclimate3025

Faletehan, A. F., Van Burg, E., Thompson, N. A., \& Wempe, J. (2020). Called to Volunteer and Stay Longer: The Significance of Work Calling for Volunteering Motivation and Retention. Voluntary Sector Review, 12, 235-255. https://doi.org/10.1332/204080520X15929332587023

Fang, W., Ng, E., Wang, C. M., \& Hsu, M. L. (2017). Normative Beliefs, Attitudes, and Social Norms: People Reduce Waste as an Index of Social Relationships When Spending Leisure Time. Sustainability, 9, 2-18. https://doi.org/10.3390/su9101696

Gammoh, B. S., Okoroafo, S. C., \& Koh, A. C. (2019). Cultural Influences on Environmental Consciousness and Green Environmental Behavior. International Journal of Marketing Studies, 11, 20. https://doi.org/10.5539/ijms.v11n1p20

Guiney, M. S., \& Oberhauser, K. S. (2009). Conservation Volunteers' Connection to Nature. Ecopsychology, 1, 187-197. https://doi.org/10.1089/eco.2009.0030

Huang, L. H. (2018). Well-Being and Volunteering: Evidence from Aging Societies in Asia. Social Science and Medicine, 229, 172-180.

https://doi.org/10.1016/j.socscimed.2018.09.004

Huppert, F. A., \& So, T. T. C. (2013). Flourishing across Europe: Application of a New Conceptual Framework for Defining Well-Being. Social Indicators Research, 110, 837 - 
861. https://doi.org/10.1007/s11205-011-9966-7

Koss, R. S., \& Kingsley, J. Y. (2010). Volunteer Health and Emotional Wellbeing in Marine Protected Areas. Ocean \& Coastal Management, 53, 447-453. https://doi.org/10.1016/j.ocecoaman.2010.06.002

Kragh, G., Stafford, R., Curtin, S., \& Diaz, A. (2016). Environmental Volunteer Well-Being: Managers' Perception and Actual Well-Being of Volunteers. F1000Research, 5, 1-25. https://doi.org/10.12688/f1000research.10016.1

Larson, L. R., Cooper, C. B., Futch, S., Singh, D., Shipley, N. J., Dale, K., \& Takekawa, J. Y. (2020). The Diverse Motivations of Citizen Scientists: Does Conservation Emphasis Grow as Volunteer Participation Progresses? Biological Conservation, 242, 1-10. https://doi.org/10.1016/j.biocon.2020.108428

Law, B. M. F., Shek, D. T. L., \& Ma, C. M. S. (2013). Validation of Family, School, and Peer Influence on Volunteerism Scale among Adolescents. Research on Social Work Practice, 23, 458-466. https://doi.org/10.1177/1049731513476144

Liarakou, G., Kostelou, E., \& Gavrilakis, C. (2011). Environmental Volunteers: Factors Influencing Their Involvement in Environmental Action. Environmental Education Research, 17, 651-673. https://doi.org/10.1080/13504622.2011.572159

Lim, J. P. S., \& Ibrahim, H. M. (2020). An Exploratory Study into the Motivations of Green Volunteers at the 29th Southeast Asian Games. Asia-Pacific Journal of Innovation in Hospitality and Tourism, 9, 73-101.

Lovell, R., Depledge, M., \& Maxwell, S. (2018). Health and the Natural Environment: $A$ Review of Evidence, Policy, Practice and Opportunities for the Future. http://hdl.handle.net/10871/36923

Lu, J., \& Schuett, M. A. (2014). Examining the Relationship between Motivation, Enduring Involvement and Volunteer Experience: The Case of Outdoor Recreation Voluntary Association. Leisure Sciences, 36, 68-87. https://doi.org/10.1080/01490400.2014.860791

McMahan, E. A., \& Estes, D. (2015). The Effect of Contact with Natural Environments on Positive and Negative Affect: A Meta-Analysis. The Journal of Positive Psychology, 10, 507-519. https://doi.org/10.1080/17439760.2014.994224

Measham, T. G., \& Barnett, G. B. (2008). Environmental Volunteering: Motivations, Modes and Outcomes. Australian Geographer, 39, 537-552. https://doi.org/10.1080/00049180802419237

Molsher, R., \& Townsend, M. (2016). Short Communication Improving Wellbeing and Environmental Stewardship through Volunteering in Nature. Ecohealth, 13, 151-155. https://doi.org/10.1007/s10393-015-1089-1

Nunnally, J. C. (1997). The Study of Change Evaluation Research: Principle Concerning Measurement Experimental Design and Analysis. In E. L. Struening, \& M. Guttentag (Eds.), Handbook of Evaluation Research. Sage.

O’Brien, L., Townsend, M., \& Ebden, M. (2010). “Doing Something Positive”: Volunteers' Experiences of the Well-Being Benefits Derived from Practical Conservation Activities in Nature. Voluntas, 21, 525-545. https://doi.org/10.1007/s11266-010-9149-1

Patrick, R., Henderson-Wilson, C., \& Ebden, M. (2021). Exploring the Co-Benefits of Environmental Volunteering for Human and Planetary Health Promotion. Health Promotion Journal of Australia, 1-11. https://doi.org/10.1002/hpja.460

Pillemer, K., Fuller-Rowell, T. E., Reid, M. C., \& Wells, N. M. (2010). Environmental Volunteering and Health Outcomes over a 20-Year Period. The Gerontologist, 50, 594-602. https://doi.org/10.1093/geront/gnq007 
Piyapong, J. (2019). Factors Affecting Environmental Activism, Nonactivist Behaviors, and the Private Sphere Green Behaviors of Thai University Students. Education and Urban Society, 52, 619-648. https://doi.org/10.1177/0013124519877149

Rusk, R. D., \& Waters, L. (2015). A Psycho-Social System Approach to Well-Being: Empirically Deriving the Five Domains of Positive Functioning. The Journal of Positive Psychology, 10, 141-152. https://doi.org/10.1080/17439760.2014.920409

Schwartz, S. H. (2012). An Overview of the Schwartz Theory of Basic Values. Online Readings in Psychology and Culture, 2, 1-20. https://doi.org/10.9707/2307-0919.1116

Seligman, M. (2011). PERMA-A Well-Being Theory by Martin Seligman. https://www.habitsforwellbeing.com/perma-a-well-being-theory-by-martin-seligman

Smetana, J. G., Campione-Barr, N., \& Metzger, A. (2006). Adolescent Development in Interpersonal and Societal Contexts. Annual Review of Psychology, 57, 255-284. https://doi.org/10.1146/annurev.psych.57.102904.190124

Smith, K., Holmes, K., Haski-Leventhal, D., Cnaan, R. A., Handy, F., \& Brudney, J. L. (2010). Motivations and Benefits of Student Volunteering: Comparing Regular, Occasional, and Non-Volunteers in Five Countries. Canadian Journal of Nonprofit and Social Economy Research, 1, 65-81. https://doi.org/10.22230/cjnser.2010v1n1a2

Stern, P. C. (2000). Toward a Coherent Theory of Environmentally Significant Behavior. Journal of Social Issues, 56, 407-424. https://doi.org/10.1111/0022-4537.00175

Van Goethem, A. A. J., Van Hoof, A., Van Aken, M. A. G., De Castro, B. O., \& Raaijmakers, Q. A. W. (2014). Socialising Adolescent Volunteering: How Important Are Parents and Friends? Age Dependent Effects of Parents and Friends on Adolescents' Volunteering Behaviours. Journal of Applied Developmental Psychology, 35, 94-101. https://doi.org/10.1016/j.appdev.2013.12.003

Vicente-Molina, M. A., Fernández-Sainz, A., \& Izagirre-Olaizola, J. (2018). Does Gender Make a Difference in Pro-Environmental Behavior? The Case of the Basque Country University Students. Journal of Cleaner Production, 176, 89-98. https://doi.org/10.1016/j.jclepro.2017.12.079

Wong, P. T. P. (2011). Positive Psychology 2.0: Towards a Balanced Interactive Model of the Good Life. Canadian Psychology, 52, 69-81. https://doi.org/10.1037/a0022511

Woosnam, K. M., Strzelecka, M., Nisbett, G. S., \& Keith, S. J. (2019). Examining Millennials' Global Citizenship Attitudes and Behavioral Intentions to Engage in Environmental Volunteering. Sustainability, 1, 13-16. https://doi.org/10.3390/su11082324

Xiao, C., \& Hong, D. (2018). Gender Differences in Environmental Behaviors among the Chinese Public: Model of Mediation and Moderation. Environment and Behavior, 50, 975-996. https://doi.org/10.1177/0013916517723126

Xiao, C., \& McCright, A. M. (2015). Gender Differences in Environmental Concern: Revisiting the Institutional Trust Hypothesis in the USA. Environment and Behavior, 47, 17-37. https://doi.org/10.1177/0013916513491571 